University of Nebraska - Lincoln

DigitalCommons@University of Nebraska - Lincoln

8-1992

\title{
The Roles of Ecological and Evolutionary Influences in Providing Structure to Parasite Species Assemblages
}

John J. Janovy Jr.

University of Nebraska - Lincoln, jjanovy1@unl.edu

Richard E. Clopton

Peru State College, RClopton@peru.edu

Tamara J. Percival Cook

Sam Houston State University, tcook@shsu.edu

Follow this and additional works at: https://digitalcommons.unl.edu/bioscijanovy

Part of the Parasitology Commons

Janovy, John J. Jr.; Clopton, Richard E.; and Percival Cook, Tamara J., "The Roles of Ecological and Evolutionary Influences in Providing Structure to Parasite Species Assemblages" (1992). John Janovy Publications. 31.

https://digitalcommons.unl.edu/bioscijanovy/31

This Article is brought to you for free and open access by the Papers in the Biological Sciences at DigitalCommons@University of Nebraska - Lincoln. It has been accepted for inclusion in John Janovy Publications by an authorized administrator of DigitalCommons@University of Nebraska - Lincoln. 


\title{
THE ROLES OF ECOLOGICAL AND EVOLUTIONARY INFLUENCES IN PROVIDING STRUCTURE TO PARASITE SPECIES ASSEMBLAGES*
}

\author{
J. Janovy, Jr., R. E. Clopton, and T. J. Percival \\ School of Biological Sciences, University of Nebraska-Lincoln, Lincoln, Nebraska 68588-0118
}

ABSTRACT: Parasite species assemblages currently are thought to range from isolationist to interactive, their dynamic properties being related to the number of species and types of hosts involved. The literature contains few experimental tests of this concept, however, and many of the host/parasite systems studied to date are not amenable to experimental manipulation. In this review, the presence of a parasite species, in a sample of host individuals, is considered to be an evolutionary phenomenon, but the parasite's population structure is considered to be an ecological one. Studies that allow evaluation of these 2 influences are comparative in nature and include data from a series of homogeneous samples of host populations. A lottery model is presented, in which hosts acquire their assemblages of parasites by Monte Carlo type sampling from multiple kind arrays; the major structuring influence is the relative probability of becoming infected by various parasite species. Claims of parasite species interaction need to be supported by studies showing departures from the predictions of this model. The species density and infraassemblage diversity index distributions are recommended as quantitative tools useful in such work.

The purpose of this paper is 2-fold: first, to evaluate the current conceptual framework of parasite assemblage ecology, particularly within the context of parasite evolutionary history, and, second, to propose some simplifying modifications of that framework. These objectives will be approached by summarizing a representative body of literature on parasite species assemblages; presenting some generalizations derived from that literature; suggesting study designs, sampling strategies, and quantitative tools that might help investigators sort through the various factors operating to provide structure to a parasite assemblage; and finally by reviewing a case study that illustrates the points made. In this paper, groups of parasite species occupying a single host individual, population, or species are referred to as assemblages, rather than communities, because interactions, beyond use of a common resource, have been unequivocally demonstrated in so few cases (although implied or inferred in many cases).

\section{THE CURRENT CONCEPTUAL FRAMEWORK AS REVEALED BY THE LITERATURE}

To describe an assemblage, one needs, as a minimum: (1) the number of species; (2) the rel-

Received 11 November 1991; revised 28 January 1992; accepted 17 February 1992.

* Paper from the von Ihering Centenary Symposium on parasite biogeography and coevolution presented at the 1991 annual meeting of the American Society of Parasitologists. ative number of individuals of each species; (3) the species' niche breadths in the presence and absence of other species, as well as their reciprocal overlaps on various linearly measurable resources, together commonly taken as a first measure of potential interaction between assemblage members; (4) the species density and infraassemblage diversity distributions; and, (5) the species names. These minimal requirements apply to virtually all species assemblages, parasitic or free living, regardless of the level, although species density and infraassemblage diversity distributions obviously require data from a group of host individuals, in the case of parasites, or from a sample of grid squares, transect intervals, or other sampling units, in the case of free-living organisms.

Species richness and potential interactions are described easily by quantitative measures such as diversity, niche breadth, and overlap indices (Pielou, 1966; Levins, 1968). Niche breadths and overlaps have not been used extensively in the analysis of parasite species assemblages, however, possibly because of the difficulty in defining resources, aside from intestinal length, that can be measured linearly (but see Schad, 1963; Hair and Holmes, 1975; Price, 1980; Janovy et al., 1991). And, given the number of papers published on parasite assemblages in the past decade, it is quite surprising how few give species density or infraassemblage diversity distributions. Thus, the conceptual framework of current literature is shaped in part by parasitologists' failure to use all of the analytical tools readily available to ecol- 
ogists in general. A careful examination of many published data sets suggests a need for an accepted minimum set of descriptors, e.g., the above. The descriptor values can then be considered the structure of a given assemblage.

The structure of parasite species assemblages is influenced by both evolutionary and ecological forces, and it is not always easy to separate the relative contributions of these 2 organizing factors. Thus, a group of parasite species might occur in a series of sympatric hosts because those hosts share evolutionary histories, or share biochemical/physiological properties that may or may not reflect a common ancestry, or simply occupy the same habitat as some generalist parasites. The literature reflects this complex array of potential organizing mechanisms, as well as the diversity of host/parasite systems studied. The latter has been a rather important feature of recent research efforts, and particularly of the interpretation of field studies. For example, Esch et al. (1990) arranged their volume Parasite Communities: Patterns and Processes along traditional taxonomic lines (parasites of molluscs, marine fish, freshwater fish, amphibians and reptiles, birds, and mammals). There is some justification for such an approach; for example, the larval trematode species assemblages of snails seem to obey quite different organizational rules than do those of aquatic birds (see Bush and Holmes, 1986a, 1986b; Stock and Holmes, 1987a, 1987b; Kuris, 1990; Fernandez and Esch, 1991a, 1991b). However, analysis by host phylum or class has led also to very large-scale generalizations, inclusiveness of which may hide valuable underlying processes discernible only on smaller scales (see Kennedy et al., 1986; Bush et al., 1990).

The growing interest in parasite "community" ecology has spawned a lively debate over the nature of parasite assemblages, with particular emphasis on the question of whether the member species interact with one another. In general, endothermic hosts tend to have relatively rich parasite faunas, in which at least the potential for interaction within a host individual evidently exists (Holmes, 1973, 1987). For example, Stock and Holmes (1987a, 1987b, 1988) reported 34 species of helminths in grebes (23 of these being cestodes), Bush and Holmes (1986a, 1986b) reported 52 helminth species ( 45 of them cestodes) and "slightly less than one million individuals" from a sample of 45 lesser scaup, and Pence and Windberg (1984) listed 20 intestinal helminth species in coyotes from southern Texas (however, see Kennedy and Bakke [1989] on the parasites of gulls). These numbers might well be significantly larger if ecto- and histozoic parasites were included in the studies.

On the other hand, the parasite assemblages of ectothermic animals, and especially invertebrates, tend to be relatively depauperate. Fernandez and Esch (1991a, 1991b) reported 8 larval trematode species in the pulmonate snail Helisoma anceps; in a very large sample of freshwater fishes, Leong and Holmes (1981) listed an average of 9.6 species of parasites (including leeches, parenteral larval forms, monogeneans, and copepods) per host species; and Aho's (1990) summary of amphibian parasites shows an average of 7.6 parasite species per host species in salamanders, frogs, and toads.

Those who study rich assemblages often have interpreted them as potentially interactive and structured at least in part by interference or exploitation competition. Those whose work has focused on depauperate assemblages usually have considered them as noninteractive, being composed largely of site specialists (Price, 1984; Kennedy, 1985; Janovy and Hardin, 1988; Holmes, 1990; Janovy et al., 1990, 1991). Attempts to develop a general theory of parasite assemblage ecology that would encompass this apparent diversity have led not only to the concept of a gradient of community types, from isolationist to interactive (Holmes and Price, 1986), but also to a search for assemblage descriptors (e.g., various similarity indices, core and satellite species models), appropriate study designs, and applicable mathematical models (Lotz and Font, 1985, 1991; Dobson and Beveridge, 1987; Esch et al., 1990; Janovy et al., 1990).

The first, and perhaps most important, observation made by investigators studying parasite assemblages is that of the parasite and host species involved. Thus the occurrence of a parasite in a host is the event that must be explained initially. Parasites recognize, biochemically and ontogenetically, the hosts in which they evolved. But parasites also respond by growth and reproduction to those hosts, including, in a few cases, fluid-filled glass ones, that give them the chemical and physical environment that turns on the right genes at the right time. If host species $A$ is the only one in which parasite species $X$ can exist, then that $1: 1$ correspondence has a certain cleanliness to it and suggests a coevolved history. But when parasite species $\mathrm{X}$ cannot distinguish 
among host species $\mathrm{A}, \mathrm{B}, \mathrm{C}$, and $\mathrm{D}$, then this behavior muddles the picture and makes it difficult to separate proximal from ultimate explanations for cooccurrence. This situation is particularly problematical when $\mathrm{A}, \mathrm{B}, \mathrm{C}$, and $\mathrm{D}$ are not closely related, for example, the mammals on the host lists for Leishmania donovani and Hymenolepis diminuta, or when single host species, such as Sturnus vulgaris or Gambusia affin$i s$, are evidently hospitable to parasite species described from hosts related only at high taxonomic levels.

Researchers have adopted concepts such as "preadaptation," "host switching," and "host capture" to describe apparent anomalies in host/ parasite combinations. These terms are in part evidence of recognition of the role of metabolic libertinism in the establishment and maintenance of parasitic relationships (Brooks, 1988; Brooks and McLennan, 1991). All large parasitological information sets contain species lists that suggest occupation, if not colonization in the evolutionary sense, of host species other than the one in which a parasite species, or its ancestors, is presumed to have evolved (e.g., The Index-Catalog of Medical and Veterinary Zoology, United States Department of Agriculture and U.S. Government Printing Office, 1932-1982; Yamaguti, 1971; Schmidt, 1986). In many cases, the occupied hosts do not appear to form a monophyletic group. The literature of parasitology contains no general, heuristic, testable, and nonteleological explanation for why some parasite species are highly discriminatory and others are not. Such a theoretical gap exists in part because parasitologists have not been particularly interested in discovering why a parasite species does not survive in a strange host. Thus the experimental work needed to define biochemically the word "generalist" has not been done. One of the parasite ecologists's great challenges is to discover just how the occupation of optional host species contributes to the maintenance of a parasite species assemblage. One of the evolutionist's great challenges is to discover the speciation potential of nondiscriminatory parasites in odd hosts. The experimental work on nonsurvival would likely contribute much to both of these tasks.

Perhaps the second most important consideration, in the initial study of parasite assemblages, is the range of life cycles involved. Parasites often exhibit complex life cycles consisting of ontogenetic events that are genetically con- trolled and thus of evolutionary origin. Life cycle events are highly vulnerable to disruption by abiotic conditions, a principle applied historically to management and control of infectious disease. The relationship between life cycle features and assemblage structure, however, is a basic biological problem that has not been explored very extensively (e.g., cf. Cone and Burt, 1981; Cusak, 1986). The parasites of Fundulus zebrinus, a fish that occupies a fluctuating environment, can serve as an example of the way ecological events can act on life cycle traits to provide structure to a parasite species assemblage. The parasites are Posthodiplostomum minimum, a trematode, and a gill monogene Salsuginus thalkeni. Although the fish plays host to several other parasite species (Janovy and Hardin, 1987, 1988), these 2 can be considered an assemblage consisting of 1 generalist and 1 specialist.

Figure 1 shows annual prevalence of the 2 parasites and Platte River streamflow, versus time, over a several-year period (Janovy and Hardin, 1987, 1988; and unpublished subsequent observations). Flow in this case is expressed as annual daily average cubic feet per second at the gauging station nearest the study site. Thus in 1983, the Platte flowed for a whole year at an average of 2,317 cubic feet per second, whereas in the years prior, and in recent years, it has flowed, for an entire year, at about one-tenth that rate. Prevalence of the extreme specialist $S$. thalkeni remained relatively high, i.e., between 50 and $90 \%$, regardless of streamflow fluctuation, but that of the generalist $P$. minimum exhibited order of magnitude fluctuations that lagged by a year or 2 those of the river. The mean intensity graphs of these parasites show the same patterns, except even more dramatically. In high prevalence years, $P$. minimum averaged at least 100 parasites per fish, whereas $S$. thalkeni averaged about 12 , regardless of prevalence (Fig. 2). In the fish, the 2 parasite species appear to be $r$ and $k$ strategists, respectively (Ricklefs, 1979), but in fact $P$. minimum is doing only what virtually all trematodes do, namely reproducing asexually in the molluscan host, whose local population in turn booms or busts in the Platte depending on Rocky Mountain snowpack. And in the case of $S$. thalkeni, infrapopulations can be as high as 60 worms, suggesting that carrying capacity is not a property of the fish, but of the physical environment. The response of both species to basically abiotic factors produces a rearrangement of relative abundances with fluctuating streamflow, that is, a 


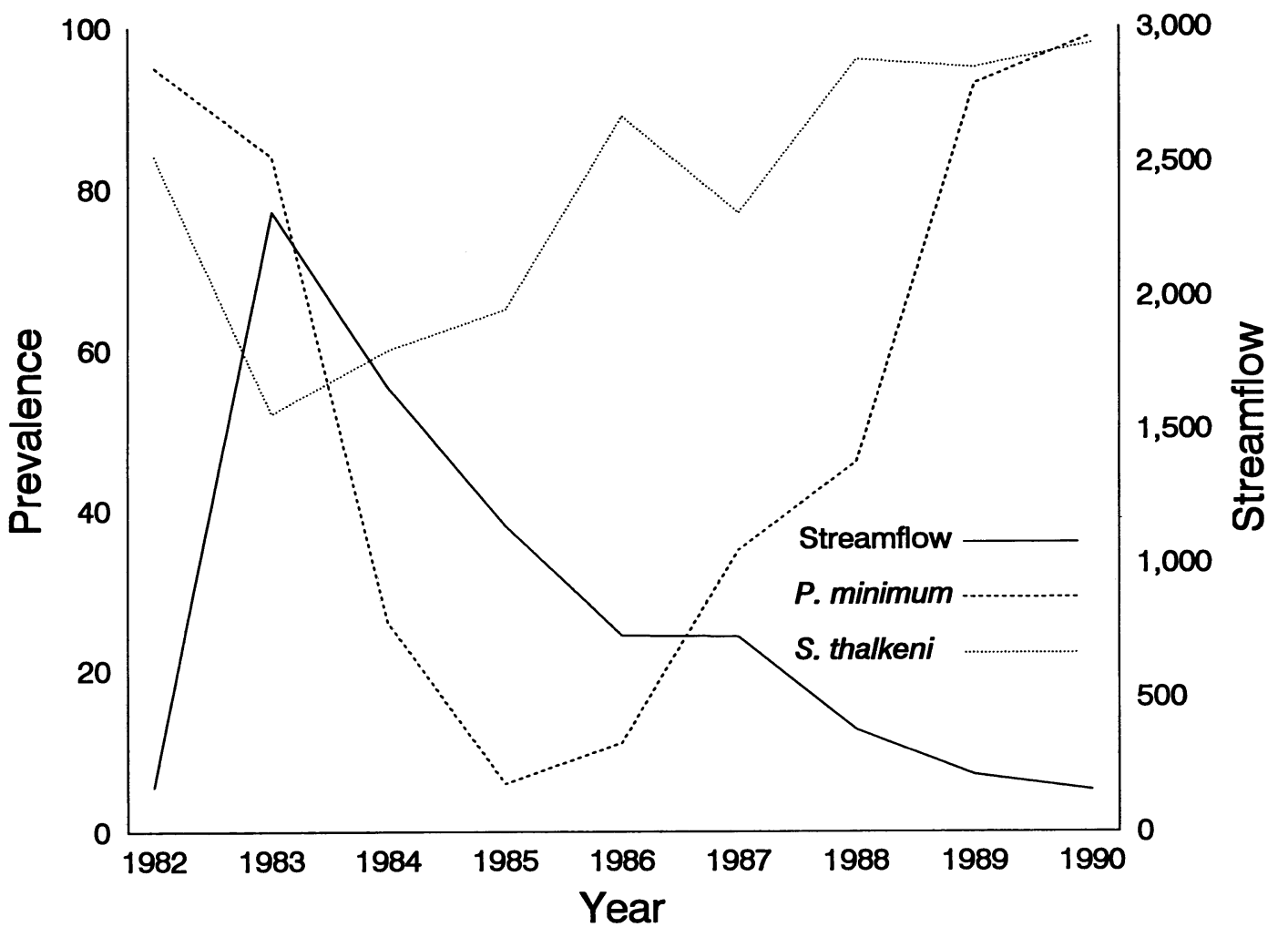

FIGURE 1. Long-term variations in prevalence of Posthodiplostomum minimum and Salsuginus thalkeni in Fundulus zebrinus from the South Platte River at Roscoe, Nebraska, and streamflow of the river expressed as average annual daily cubic feet per second at the gauging station nearest the collection site. Data are from Janovy and Hardin $(1987,1988)$ and subsequent unpublished observations.

life-history-mediated change in assemblage structure.

\section{SIMPLIFYING GENERALIZATIONS SUGGESTED BY THE LITERATURE}

Parasite species assemblages have 2 basic components: the species themselves and the various species' population structures. The presence of a parasite is proof that the chemical and physical environment provided by the host is adequate to support the parasite, at least temporarily. Both parasite requirements and host biochemical and physiological properties are manifestations of genotype, thus evolutionary history, although their complementarity is not necessarily a product of coevolution (Brooks and McLennan, 1991). The proximal factors that control the host/parasite encounter, however, are largely ecological. Thus it might be said that the presences, including the potential presences, of parasite species in a host species are evolutionary phenomena, whereas the parasites' population structures, including void frequency distributions, are ecological ones. And unless interaction between parasite species is clearly demonstrated, hopefully experimentally, at either the infra-, component, or supra-assemblage levels, then such interaction remains hypothetical, and the source of assemblage structure must be sought in local environmental conditions, including those within the host, that influence individual parasite species' populations.

These generalizations actually are extensions of the first principles, outlined above, that are widely applicable to symbiotic relationships. The literature of parasite ecology is characterized by its paucity of experimental tests of these principles and the abundance of post-hoc observations of their apparent operation (see references in Esch et al., 1990). But in fairness to past investigators, it is important to recognize just how difficult it is to domesticate parasites and their hosts, or to do meaningful field experiments on them. By field experiments is meant those rou- 


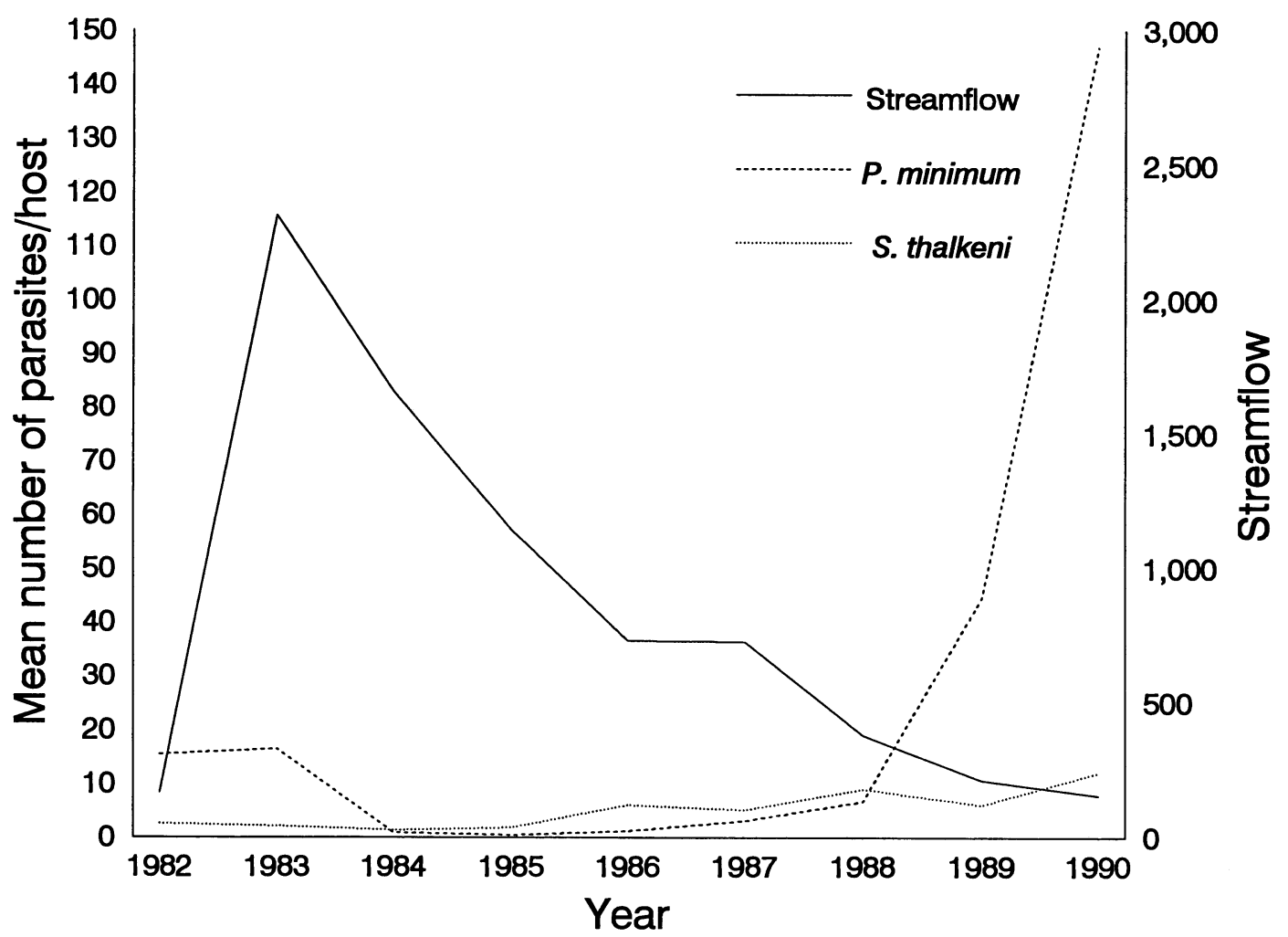

FIGURE 2. Long-term variations in mean number of parasites per host, for Posthodiplostomum minimum and Salsuginus thalkeni in Fundulus zebrinus from the South Platte River at Roscoe, Nebraska, and streamflow of the river expressed as average annual daily cubic feet per second at the gauging station nearest the collection site. Data are from Janovy and Hardin $(1987,1988)$ and subsequent unpublished observations.

tinely employed by ecologists, for example replicate enclosures or exclusion cages and replicate disturbances (cf. Hairston, 1986; Day et al., 1991). In fact, some of the richest and most interesting systems, such as large carnivores and aquatic birds and their parasites, may be impossible to experiment on in any meaningful way with respect to their parasite assemblage ecology. Thus although some evidence for interactions is seen in speciesrich infraassemblages, it still must be shown that these observations are of either long-term ecological or evolutionary significance, and the systems themselves may not really be tractable enough to do the needed research. It seems that one of our most important tasks is to search for host/parasite systems that can be manipulated in field experiments and perhaps controlled for long periods.

\section{THE DESIGN OF RELEVANT STUDIES}

Regardless of whether they are experimental or post hoc, studies that help reveal the relative contributions of evolution and ecology (1) are comparative, (2) involve some host species that are related (according to current taxonomic schemes), (3) include some sympatric host species, (4) rely on data collected as a series of relatively homogeneous samples, and (5) are conducted with the intent to discover the manner in which various species of parasites are distributed among a community of host species.

These studies are especially valuable if published in a journal that allows data to be presented in some relatively raw manner or if the investigator saves the original data set and allows colleagues to borrow it. Although the original numbers may not change, the methods and intents of analysis do evolve, and a highly summarized data set may hide information that would be of significance to later workers, including theoreticians (e.g., see Holl, 1932).

A significant fraction of published papers have at least some of the above characteristics, but very few have all, and a large number are plagued 
by use of heterogeneous host samples (see references in Esch et al., 1990). Heterogeneity is a major problem in field studies, although logistical difficulty, rather than malintent, is obviously the source in most cases. Gerald Kutish, searching for data sets to use in theoretical studies (Janovy and Kutish, 1988), developed the guideline that homogeneous field samples are those from hosts taken at a single location within a time shorter than that of the parasite's life cycle. Although even hosts collected the same fraction of a second may contain overlapping parasite generations, the only way to avoid this problem is through controlled infections, and then the data are no longer field data. Hosts collected over a greater length of time than that required for completion of the parasite's life cycle, and combined into a single sample, by definition constitute a heterogeneous sample. Much of the heterogeneity in this case likely originates in the changing effects of abiotic conditions on transmission, as in the $P$. minimum example.

The distributions of parasite species among ecologically or taxonomically related host species have been described in numerous ways (Esch et al., 1990) but not always in a manner that allows meaningful statistical comparison. Similarity indices such as Jaccard's do not contribute very much to an understanding of the relationship between ecological and evolutionary processes when single heterogeneous samples from disjunct regions are compared. Species density distributions are rarely presented and even more rarely compared statistically (but see Lotz and Font, 1985, 1991). These distributions routinely are fit by discrete approximations of normal distributions; thus unlike many field data sets in parasitology, they can be analyzed using normal statistics without transformation. They easily can become truly powerful experimental tools, even for nonexperimental field work, but would be especially valuable in studies on systems that can be manipulated to alter ecologically the prevalence of 1 of more parasite species. Potentially included in this category, of course, are systems of agricultural importance.

A second quantitative tool that has been used rarely by parasitologists, but nevertheless has great potential for use in trying to sort out the relative contributions of evolution and ecology in parasite assemblage dynamics, is the frequency distribution of infraassemblage diversity. In theory, in a series of homogeneous samples, the diversity index distribution ought to assume dif- ferent shapes according to the influence of various ecological conditions on assemblage diversity, whether it be at the infra- or component levels. There are very few parasite ecology papers, however, that give means and variances for infraassemblage diversity distributions in different populations of the same host species, or in sympatric populations of different host species, although the data had to have been gathered in a great many cases (references in Esch et al., 1990). This distribution thus appears to be an underutilized tool that, like the species density distribution, could provide quite a bit of statistical power to properly designed field studies.

Both the species density and infraassemblage diversity distributions should be able to be made to assume different shapes in experimentally manipulated systems, including those involving hosts of agricultural importance. But before the infraassemblage diversity index distribution can be used as a tool, it is necessary to have a method for generating expected, or theoretical, distributions. At present there does not appear to be a method for doing this, aside from Monte Carlo simulations (Bowman et al., 1971; Janovy et al., 1990), but such a lack should inspire efforts to develop appropriate mathematical models for use in parasite ecology.

\section{A CASE STUDY}

A relatively familiar study that has most of the above characteristics needed to evaluate the relative role of ecological vs. evolutionary influences on assemblage structure is that of Goater et al. (1987). The intent was to examine the parasite assemblages of 4 host species sympatric in southern Appalachian streams. This work is of special interest, in addition, because it was inspired in part by the extensive research on host ecology (Hairston, 1949, 1986; Martof and Scott, 1957; Martof, 1962).

Ten species of helminths are shared by 4 salamander species, although in most cases prevalence is low (Table I) so that opportunities for interaction between parasite species are limited, and the assemblages were considered to be isolationist. The parasite assemblages were presented as species-density histograms, in which parasite species/host classes were plotted on the $\mathrm{X}$-axis and frequencies on the $\mathrm{Y}$-axis. In hosts of 3 species, Leurognathous marmorata, Desmognathus monticola, and Desmognathus ochrophaeus, these distributions were described accurately by the Poisson distribution, but in the 
TABLE I. Members of the parasite species assemblage of salamanders as reported by Goater et al. (1987). The prevalences are for infections in Desmognathus quadramaculatus, adult forms of parasites.

\begin{tabular}{lc}
\hline $\begin{array}{c}\text { Evolutionary events } \\
\text { (parasite species present) }\end{array}$ & $\begin{array}{c}\text { Ecological events } \\
\text { (prevalences) }\end{array}$ \\
\hline Capillaria inequalis & 0.85 \\
Desmognathinema nantahalaensis & 0.37 \\
Thelandros magnavulvaris & 0.31 \\
Omeia papillocauda & 0.13 \\
Cosmocercoides dukae & 0.06 \\
Phyllodistomum solidum & 0.06 \\
Cylindrotaenia americana & 0.06 \\
Gorgoderina bilobata & 0.03 \\
Brachycoelium elongatum & 0.02 \\
Falcaustra plethodontis & 0.01 \\
\hline
\end{tabular}

fourth, Desmognathus quadramaculatus, they were not (Figs. 3, 4).

Although some of the species-density histograms fit Poisson distributions, technically, they are not Poisson distributions at all. Instead, they are described accurately by a model that randomly samples a multiple-kind array that includes blank slots (Fig. 5) and in which the probability of being infected can vary among parasite species. Thus the probability of parasites $A$ and $B$ but not $C$ is not necessarily the same as the probability of parasites $\mathrm{A}$ and $\mathrm{C}$ but not $\mathrm{B}$. This fact makes the probability generating function a computational monster for a species-rich assemblage. When 16 species of parasites are involved, 65,536 separate calculations are required to obtain the theoretical values for fitting species density distributions. Such systems are similar to the lottery models used to explain, for example, the occupation of territories on reefs by various fishes, with the exception that the host's sampling scheme allows for failure to acquire parasites (cf. Sale, 1978).

The field data from Goater et al. (1987) clearly illustrate the underlying principle for assemblage organization that the presence of a parasite is an evolutionary phenomenon, whereas the population structure is of ecological origin. The parasite species mostly are generalists, usually occurring in salamanders, but if the literature is an accurate reflection of nature, some are found also in anurans and reptiles. It is not trivial to assert that this assemblage would not likely occur in fish, mink, shrews, or wrens that live in and along the streams where Goater collected. That is, the assemblage itself is characteristic of a group of related hosts. The 4 species of salamanders evidently "select," generally at random, from the

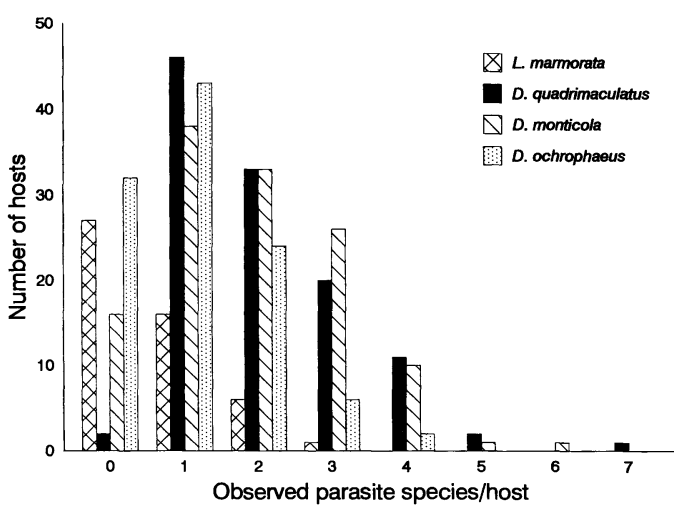

FIgURE 3. Species density distributions for the helminth assemblages of 4 sympatric species of salamanders, Leurognathous marmorata, Desmognathus monticola, Desmognathus ochrophaeus, and Desmognathus quadramaculatus. Figure is redrawn from Goater et al. (1987).

same smorgasboard of helminths along some southern Appalachian streams, but their selection patterns differ, presumably according to their own ecological requirements (see Hairston, 1949, 1986; Martof and Scott, 1957; Martof, 1962).

In this case study, even when assemblage structure seems to depart from the smorgasboard model, a careful and comparative examination of the numbers suggests that departure may have its origins in either the investigator's sampling

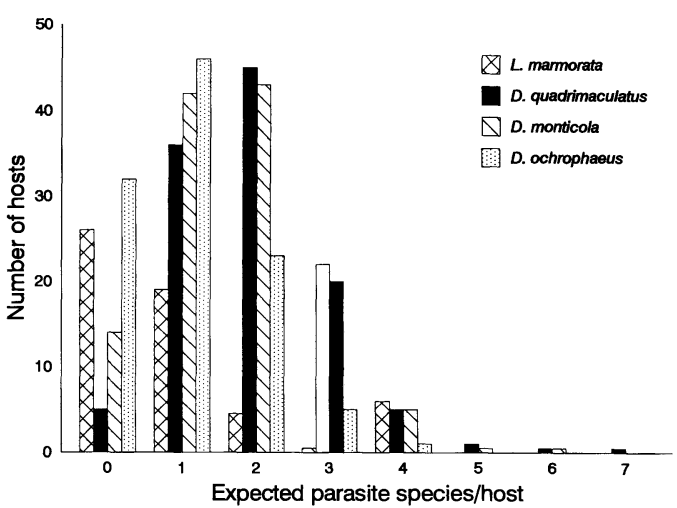

FIGURE 4. Expected species density distributions for the helminth assemblages of 4 sympatric species of salamanders, Leurognathous marmorata, Desmognathus monticola, Desmognathus ochrophaeus, and Desmognathus quadramaculatus. Probabilities for species per host classes were determined by summing probabilities for each possible combination of species, using observed prevalences as probabilities of a singlespecies infection. Frequencies were calculated by multiplying species per host classes' probabilities times sample size. Field data are from Goater et al. (1987). 


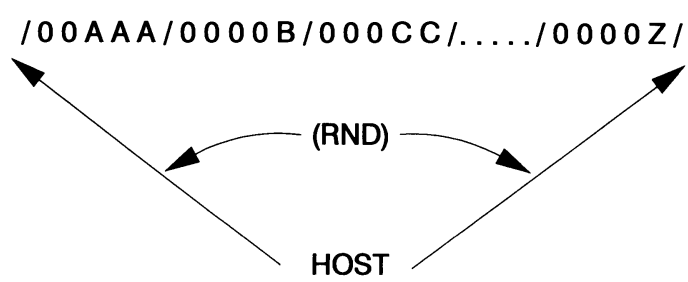

FIGURE 5. Lottery model for a host's random "selection" of parasites from a multiple species array. Parasites are represented by letters; species are A, B, C, etc.; each letter within a species represents an individual parasite; zeros are blank slots that allow for a host's failure to become infected. Parasite species are present in different relative proportions, letters to zeros, corresponding to their prevalences. RND means that the angle of the selection arrow (which in turn points to a parasite or blank slot selected) is drawn from a uniform random distribution for each selection event.

strategy or in some local ecological event whose evolutionary significance must be demonstrated before being claimed. For example, the D. quadramaculatus data do not fit the expected frequency distribution because there are more single parasite species infections, and fewer 2-species infections, than would be expected from the relative probabilities of infection by the various members of the assemblage, as estimated by their prevalences (Figs. 3, 4). This observation seems to provide evidence for competition lending structure to the assemblage. But the data also allow an alternate interpretation in which this discrepancy is due to a natural set of events the influence of which is seen in the seasonal changes in the frequency of 1-, 2-, and 3-species infections. These infections involve Capillaria inequalis, Thelandros magnavulvaris, and Desmognathinema nantahalensis, the 3 most prevalent parasites.

In April and May, infections consist predominantly of 1 or 2 of these species, in June and July, 2- and 3-parasite species classes are more frequent than in the spring, and in the fall, uninfected and 1- and 2-species classes are relatively large (Fig. 6). That is, the species-density curve shifts to the right in midsummer. The potential interaction between parasite species, suggested by the lack of fit of the species density distribution to the Poisson model, actually results from heterogeneity produced by violation of the Kutish homogeneity rule (Janovy and Kutish, 1988) in the published paper (but not in the study itself). $T$-tests show that there is no difference between the mean number of parasite species per collection site, Bearpen and Curtis creeks

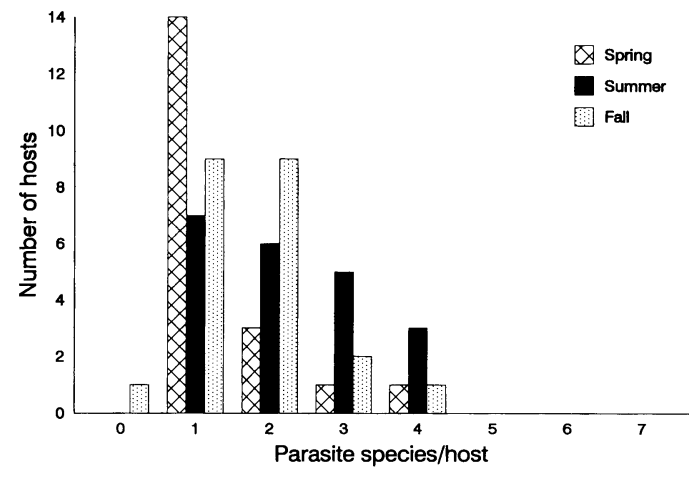

FIGURE 6. Species-density distributions as a function of season for the helminth assemblage of Desmognathus quadramaculatus. Data broken out from those reported by Goater et al. (1987).

in the Gulf of Mexico drainage system, and Abe's and Overflow creeks in the Atlantic drainage system. So the midsummer shift is a regional (southeastern United States), rather than local, phenomenon. The ability of these parasites to survive in D. quadramaculatus is explained by their evolutionary history. The form of the assemblage varies temporally but not spatially within the region, however, and this variation in form must be interpreted as being of ecological origin. The important general question derived from this analysis is: when does a variation in assemblage structure exceed its dynamic limits and become another "species" of assemblage, perhaps with a new member or two whose lives are linked inextricably to another salamander species' niche?

Although the seasonal infraassemblage diversity index distributions for D. quadramaculatus were not presented by Goater et al. (1987), they were calculated from the original data and are shown in Figure 7. These frequency distributions tend to assume the shape of those in the insert (see also Bowman et al., 1971). In the zeroth class fall those host species individuals with zero or 1 species of parasite (index formula determines this); at the far right are those individuals with relative large numbers of parasite species occurring in relatively even proportions. ANOVA using ranked $H^{\prime}$ values showed infraassemblage diversity increased significantly in the summer in this system but did not vary between sites within a sampling period. Again, the assemblage structure parameters varied temporally but not regionally, suggesting that structure was influenced most strongly by seasonal factors. If this is true, then even such biotic phenomena as interme- 


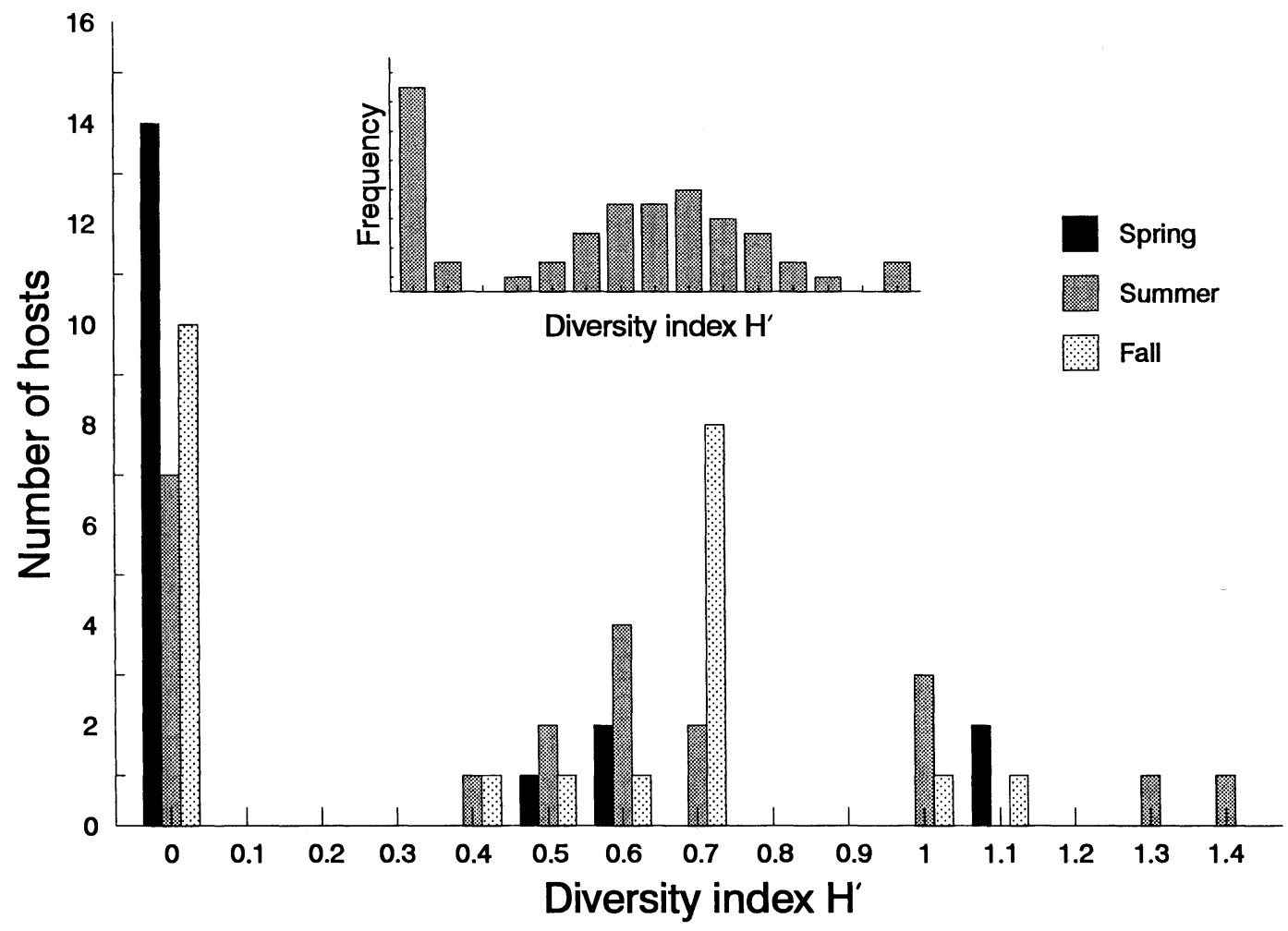

FIGURE 7. Seasonal changes in infraassemblage diversity distributions in the parasite assemblage of Desmognathus quadramaculatus. Frequencies calculated from original Goater et al. (1987) data, supplied by T. Goater. $H^{\prime}$ is the Shannon diversity index calculated using base e logs. The insert is the general form of infraassemblage diversity distributions for parasite species assemblages.

diate host availability might be considered redundant measures of temperature and moisture, i.e., reducible to abiotic influences, as could be done in the case of $P$. minimum in $F$. zebrinus, rather than coevolutionary ones.

The extensive background information on salamander ecology gives the Goater et al. (1987) study a use beyond that of illustrating assertions, namely as a stimulus for consideration of innovative approaches to the subject of this review. Parasites, of course, cannot live apart from their hosts, but from an ecological/evolutionary perspective, work such as that of Goater et al. (1987) makes one wonder about the reciprocal situation. If the parasite species assemblage cannot exist without the salamanders, could the salamanders live and reproduce along Bearpen and Curtis creeks but in micro-environments in which they would not have access to the infective stages of their parasites? The answer is very likely "no," a prediction that could be tested experimentally with tractable systems. Such a study would have great potential for strengthening any apparent coevolutionary link between host species and their parasite assemblages (as opposed to single parasite species) in that the relationship between a host's species-specific ecological niche and its parasite species assemblage might be established experimentally.

Or, in a related experiment, D. quadramaculatus could be put in the L. marmorata habitat to test the prediction that the structure of the parasite assemblage in D. quadramaculatus would then match that of the assemblage in $L$. marmorata. If the salamander literature accurately reflects the ecological requirements of these hosts, however, instead of trading parasite assemblages, $D$. quadramaculatus probably would die if transferred for a long period of time to L. marmorata's ecological niche (Hairston, 1949, 1986; Martof and Scott, 1957; Martof, 1962). This seemingly trivial speculation is actually a thought experiment suggesting an evolutionary link between the numerical structure of a parasite assemblage, the inherited life cycle and niche requirements, including abiotic ones, of the parasite species in- 
volved, and the inherited ecological requirements of the host.

Very many published data sets do not allow determination of just how widespread are the patterns described in this paper. The problem is not necessarily a failing of investigators, but it arises for a number of reasons, including traditions of data presentation in published papers, editorial policies, heterogeneity forced on researchers by logistics and host biology, and the relatively recent development of the computer as a tool for use in data analysis and modeling. But perhaps most importantly, this problem arises because parasitologists have not always done the kinds of comparisons that make the Goater et al. (1987) data set so revealing, for example between parasite assemblages in sympatric related host species, using all of the design requirements indicated above.

\section{ACKNOWLEDGMENTS}

We greatly appreciate the fact that Tim Goater and John Holmes were willing to send us original data from published papers, although only the Goater data were used.

\section{LITERATURE CITED}

Aно, J. M. 1990. Helminth communities of amphibians and reptiles. In Parasite communities: Patterns and processes, G. W. Esch, A. O. Bush, and J. M. Aho (eds.). Chapman and Hall, New York, p. 157-195.

Bowman, K. O., K. Hutcheson, E. P. Odum, and L. R. Shenton. 1971. Comments on the distribution of indices of diversity. In Statistical ecology, Vol. 3. Many species populations, ecosystems, and systems analysis, G. P. Patil, E. C. Pielou, and W. E. Waters (eds.). The Pennsylvania State University Press, University Park, Pennsylvania, p. 315359.

BRoOKS, D. R. 1988. Macroevolutionary comparisons of host and parasite phylogenies. Annual Review of Ecology and Systematics 19: 235-259.

— AND D. A. Mclennan. 1991. Phylogeny, ecology, and behavior: A research program in comparative biology. University of Chicago Press, Chicago, Illinois, $434 \mathrm{p}$.

Bush, A. O., J. M. Aho, AND C. R. Kennedy. 1990. Ecological versus phylogenetic determinants of helminth parasite community richness. Evolutionary Ecology 4: 1-20.

$\longrightarrow$ - AND J. C. Holmes. 1986a. Intestinal helminths of lesser scaup ducks: Patterns of association. Canadian Journal of Zoology 64: 132-141.

— AND —. 1986b. Intestinal helminths of lesser scaup ducks: An interactive community. Canadian Journal of Zoology 64: 142-152.

CONE, D. K., AND M. D. B. BuRT. 1981. The invasion route of the gill parasite Urocleidus adspectus
Mueller, 1936 (Monogenea: Ancyrocephalinae). Canadian Journal of Zoology 59: 2166-2171.

CUSAK, R. 1986. Development of infections of $G y$ rodactylus colemanensis Mizelle and Kritsky, 1967 (Monogenea) and the effect on fry of Salmo gairdneri Richardson. Journal of Parasitology 72: 663668.

DAy, R. W., A. BARKai, AND P. A. WiCkens. 1991. Trapping of three drilling whelks by two species of mussel. Journal of Experimental Marine Biology and Ecology 149: 109-122.

Dobson, A. P., AND I. Beveridge. 1987. The structure and evolution of parasite communities. International Journal for Parasitology 17: 991-992.

Esch, G. W., A. O. Bush, AND J. M. AHO (eds.). 1990. Parasite communities: Patterns and processes. Chapman and Hall, New York, 335 p.

FERNANDEZ, J., AND G. W. EsCH. 1991a. Guild structure of larval trematodes in the snail Helisoma anceps: Patterns and processes at the individual host level. Journal of Parasitology 77: 528-539.

— AND —. $1991 \mathrm{~b}$. Component community structure of larval trematodes in the pulmonate snail Helisoma anceps. Journal of Parasitology 77 : 540-550.

GoATer, T. M., G. W. Esch, AND A. O. Bush. 1987. Helminth parasites of sympatric salamandersEcological concepts at infracommunity, component, and compound community levels. American Midland Naturalist 118: 289-300.

HaIR, J. D., AND J. C. Holmes. 1975. The usefulness of measures of diversity, niche width and niche overlap in the analysis of helminth communities in waterfowl. Acta Parasitologica Polonica 23: 253269.

Hairston, N. G. 1949. The local distribution and ecology of the plethodontid salamanders of the southern Appalachians. Ecological Monographs 19: 47-73.

- 1986. Species packing in Desmognathus salamanders: Experimental demonstration of predation and competition. American Naturalist 127: 266-291.

Holl, F. J. 1932. The ecology of certain fishes and amphibians with special reference to their helminth and linguatulid parasites. Ecological Monographs 2: 83-107.

Holmes, J. C. 1973. Site selection by parasitic helminths: Interspecific interactions, site segregation, and their importance to the development of helminth communities. Canadian Journal of Zoology 51: 333-347.

- 1987. The structure of helminth communities. International Journal for Parasitology 17: 203 208.

-1990. Competition, contacts, and other factors restricting niches of parasitic helminths. Annales de Parasitologie Humaine et Comparée 65(suppl.): 69-72.

- AND P. W. PRICE. 1986. Communities of parasites. In Community ecology: Patterns and processes, D. J. Anderson and J. Kikkawa (eds.). Blackwell Scientific Publications, Oxford, p. 187213.

Janovy, J., JR., M. T. Ferdig, AND M. A. MCDowell. 1990. A model of dynamic behavior of a parasite 
species assemblage. Journal of Theoretical Biology 142: 517-529.

, AND E. L. HARDIN. 1987. Population dynamics of the parasites in Fundulus zebrinus in the Platte River of Nebraska. Journal of Parasitology 73: 689-696.

- AND - 1988. Diversity of the parasite assemblage of Fundulus zebrinus in the Platte River of Nebraska. Journal of Parasitology 74: 207213.

$\longrightarrow$, AND G. W. Kutish. 1988. A model of encounters between host and parasite populations. Journal of Theoretical Biology 134: 391-401.

$\longrightarrow$, M. A. MCDowell, AND M. T. Ferdig. 1991. The niche of Salsuginus thalkeni, a gill parasite of Fundulus zebrinus. Journal of Parasitology 77: 697702.

KENNEDY, C. R. 1985. Site segregation by species of Acanthocephala in fish, with special reference to eels, Anguilla anguilla. Parasitology 90: 375-390.

- AND T. A. BAKKE. 1989. Diversity patterns in helminth communities in common gulls, Larus canus. Parasitology 98: 439-445.

$\longrightarrow$, A. O. Bush, ANd J. M. Aho. 1986. Patterns in helminth communities: Why are birds and fish different? Parasitology 93: 205-215.

KuRIS, A. 1990. Guild structure of larval trematodes in molluscan hosts: Prevalence, dominance and significance in competition. In Parasite communities: Patterns and processes, G. W. Esch, A. O. Bush, and J. M. Aho (eds.). Chapman and Hall, New York, p. 69-100.

LeONG, T. S., AND J. C. Holmes. 1981. Communities of metazoan parasites in open water fishes of Cold Lake, Alberta. Journal of Fish Biology 18: 693713.

LEVINS, R. 1968. Evolution in changing environments. Princeton University Press, Princeton, New Jersey, $120 \mathrm{p}$.

Lotz, J. M., AND W. F. FonT. 1985. Structure of enteric helminth communities in two populations of Eptesicus fuscus (Chiroptera). Canadian Journal of Zoology 63: 2969-2978. , AND - . 1991. The role of positive and negative interspecific associations in the organization of communities of intestinal helminths of bats. Parasitology 103: 127-138.
MARTOF, B. S. 1962. Some aspects of the life history and ecology of the salamander Leurognathus. American Midland Naturalist 67: 1-35.

$\longrightarrow$, AND D. C. ScotT. 1957. The food of the salamander Leurognathus. Ecology 38: 494-501.

Pence, D. B., AND L. A. Windberg. 1984. Population dynamics across selected habitat variables of the helminth community in coyotes. Journal of Parasitology 70: 735-746.

Pielou, E. C. 1966. The measurement of diversity in different types of biological collections. Journal of Theoretical Biology 13: 131-144.

Price, P. W. 1980. Evolutionary biology of parasites. Princeton University Press, Princeton, New Jersey, $237 \mathrm{p}$.

- 1984. Communities of specialists: Vacant niches in ecology and evolutionary time. In Ecological communities: Conceptual issues and the evidence, D. R. Strong, D. Simberloff, L. G. Abele, and A. B. Thistle (eds.). Princeton University Press, Princeton, New Jersey, p. 510-523.

Ricklefs, R. E. 1979. Ecology. Chiron Press, Inc., Concord, Massachusetts, 966 p.

SAle, P. F. 1978. Coexistence of coral reef fishes-A lottery for living space. Environmental Biology of Fishes 3: 85-102.

SCHAD, G. A. 1963. Niche diversification in a parasite species flock. Nature 198: 404-406.

SCHMIDT, G. D. 1986. Handbook of tapeworm identification. CRC Press, Inc., Boca Raton, Florida, $675 \mathrm{p}$.

Stock, T. M., AND J. C. Holmes. 1987a. Dioecocestus asper (Cestoda: Dioecocestidae): An interference competitor in an enteric helminth community. Journal of Parasitology 73: 1116-1123. , AND —. 1987b. Host specificity and exchange of intestinal helminths among four species of grebes (Podicipedidae). Canadian Journal of Zoology 65: 669-676.

— AND —. 1988. Functional relationships and microhabitat distribution of enteric helminths of grebes (Podicipedidae): The evidence for interactive communities. Journal of Parasitology 74: 214-227.

YAMAGUti, S. 1971. Synopsis of digenetic trematodes of vertebrates, Vol. 1. Keigaku Publishing Company, Tokyo, Japan, 1,074 p. 